\title{
Image Case : Celiac Disease in 14 Years Old Girl with Type 1 Diabetes Mellitus
}

\author{
Tarik Zaher \\ Tropical Medicine Department, Faculty of Medicine, Zagazig University, Egypt. \\ tareqzaher@gmail.com
}

Celiac disease is an autoimmune disease that primarily affects the small intestine. Classic symptoms in children include gastrointestinal disorders as chronic diarrhea, malabsorption and failure to grow normally. It is associated with other autoimmune diseases, such as thyroiditis and diabetes mellitus type 1 [1]. Mild or absent gastrointestinal symptoms may be found specially in older people[2].Celiac disease may be presented with rare but life threatening crisis[3]. 14 years old underbuilt anemic (iron deficiency) girl with type 1 diabetes mellitus without gastrointestinal symptoms was endoscopicaly examined for clinical suspicion of Celiac disease. On endoscopic examination there was fissurization (cracked-mud ) of the mucosa of the duodenal bulb as well as descending duodenum. Pathological examination of the endosopic biopsies confirmed the diagnosis.

Upper gastrointestinal endoscopy in celiac disease usually shows scalloped (indentations and erosions) blunted duodenal mucosa, visible mucosal vessels, micronodular appearance of the mucosa and mucosal fissures(cracked-mud). Duodenal biopsy shows villous blunting with intraepithelial lymphocytosis[1,3].

\section{Ethical consideration:}

Consent was obtained from the case.All the information gathered from the patient was handled confidentially, and it was used only for research purpose.

\section{Funding:}

None.

Conflict of interest:

There is no conflict of interest.

\section{REFERENCES}

1. Meis M, Adamiak T. Pediatric Celiac Disease A Review. S D Med. 2018 Dec;71(12):559-564. 2. Real Delor RE.Silent Celiac Disease in an obese patient. Rev Fac Cien Med Univ Nac Cordoba. 2017 Dec 14;74(4):398-401.

3. Poudyal R, Lohani S, Kimmel WB. A case of celiac disease presenting with celiac crisis: rare and life threatening presentation. J Community Hosp InternMed Perspect. 2019 Feb 11;9(1):22-24.

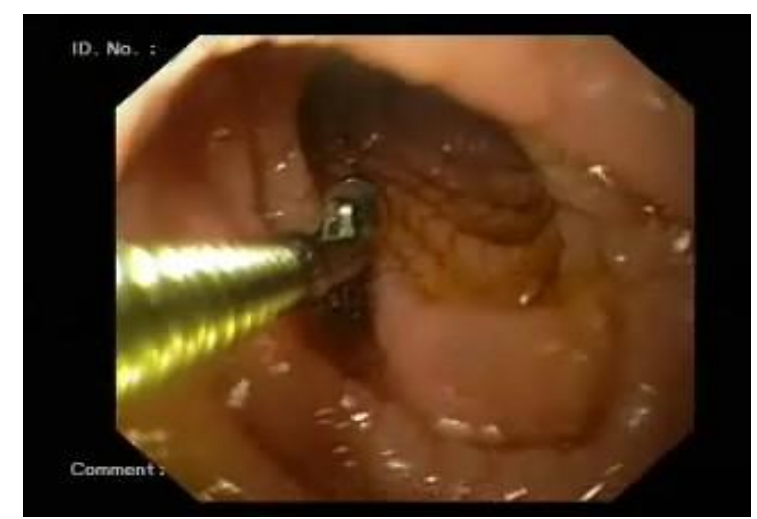

Figure(1):Cracked-mud(fissurizations) mucosa of the descending duodenum. 